\title{
Active diluents effects of 4-nonylphenoxy-1, 2-dinitrilbenzene on phthalonitrile containing benzoxazine and their copolymerization behaviors
}

\author{
M. Z. Xu, M. D. Liu, S. H. Dong, G. Y. Qiu, X. B. Liu* \\ Research Branch of Functional Materials, Institute of Microelectronic \& Solid State Electronic, High-Temperature \\ Resistant Polymers and Composites Key Laboratory of Sichuan Province, University of Electronic Science and \\ Technology of China, Chengdu 610054, P. R. China
}

Received 13 June 2013; accepted in revised form 17 August 2013

\begin{abstract}
NP-ph), a novel kind of phthalonitrile containing flexible hydrocarbyl chains, has been synthesized. The structures of NP-ph were investigated by Nuclear Magnetic Resonance Spectroscopy $\left({ }^{1} \mathrm{H}-\mathrm{NMR}\right)$ and Fourier Transform Infrared Spectroscopy (FTIR). Low viscosity NP-ph/phthalonitrile containing benzoxazine (BA-ph) blends were achieved by melt blending BA-ph with various content of NP-ph. Copolymerization behaviors and processability of NP-ph/BA-ph have been investigated by Differential Scanning Calorimetry (DSC) and Dynamic Rheological Analysis. Results indicated that NP-ph/BA-ph blends processability was improved and can be controlled by varying NP-ph contents, processing temperature and time. NP-ph/BA-ph polymers were prepared from the thermal polymerization with short curing time and low curing temperatures without addition of any other curing agents, which displayed high glass transition temperature $\left(>360^{\circ} \mathrm{C}\right)$ and attractive thermal decomposition temperature $\left(>420^{\circ} \mathrm{C}\right)$. The outstanding glass transition temperature and desirable thermo-oxidative stabilities, together with good processability and sound process conditions could enable the NP-ph/BA-ph polymers to be further explored in the fields under some practical critical circumstances with requirements of high wears and temperatures.
\end{abstract}

Keywords: thermal properties, active diluents effects, phthalonitrile, copolymer behavior, thermal mechanical properties

\section{Introduction}

Resin-transfer molding (RTM) for the fabrication of composite materials has been receiving more and more attention because of its comparatively low cost and high efficiency [1,2]. Environmentally friendly processes together with the satisfactory products resulted in a wide application of RTM in several commercial applications, from repairing bridges to making sailboats and refrigerated cargo boxes, and has been considered for various civil and marine infrastructure, aerospace, defense and automotive applications [3-5].

\footnotetext{
${ }^{*}$ Corresponding author, e-mail: liuxb@uestc.edu.cn

(C) BME-PT
}

Owing to the strict requirements of the process, most of thermosetting resins cannot satisfy the requirements of RTM [6]. Though the unsaturated polyesters, vinyl esters, and acrylates can match the characteristic of low viscosity $(<1 \mathrm{~Pa} \cdot \mathrm{s})$ and a long pot life at the injection temperature, none of these resins can meet the need of high-performance composites for strength, modulus, and thermo-oxidative stability.

Recently, phthalonitrile resin containing benzoxazine (BA-ph) was designed and synthesized via a condensation reaction between amino-functional phthalonitrile and bisphenol A [7]. Owing to the 
active phenolic hydroxyls generated from ringopening of benzoxazine, many advantages can be obtained. On the one hand, the active phenolic hydroxyls generated from ring-opening of benzoxazine can be used as a kind of curing agent to achieve the cross-linking networks, thus realizing the selfpromoted copolymerization. On the other hand, the active phenolic hydroxyls allowed BA-ph to be used as hydroxyl-functional phthalonitrile to achieve good processability and desirable properties of the composites [8-11]. Therefore, these merits accompany their excellent processability (low melting point, low viscosity), outstanding thermal stabilities and cost-effectiveness have made BA-ph resin attract increasing interests in the field of composites compared with the traditional heat resisting resins and can find their potential applications in the future [12-15].

Though the BA-ph resin showed quite low melt viscosity, the resin was still required to be further improved to reduce the melt viscosity to match the requirements of industrial applications. Thus, in our previous work, low-viscosity epoxy resin has been partially incorporated into the BA-ph resin to improve the prosessability [8]. It has been reported that the incorporation of low-viscosity epoxy resin has significantly decreased the melt viscosity and improved the impregnation characteristic of the composites [16-19]. Moreover, the low-viscosity resin also allowed addition of a greater amount of filler (e. g. nanoclay and CNTs) while maintaining processability of the molding compound [11, 20, 21]. However, in the case, the decrease of melt viscosity of the composites was at the cost of heat resistance and reaction rate $[8,20,21]$.

Recently, a novel kind of low-viscosity phthalonitrile containing a flexible aliphatic hydrocarbon segment (4-nonylphenoxy-1,2-dinitrilbenzene, NPph) has been designed and manufactured. The long aliphatic hydrocarbon segment in the NP-ph monomer resulted in the low melt temperature and viscosity. Meanwhile, the active cyano groups can be involved in the polymerization reaction of the BA-ph, resulting to the high cross-linking degree and heat resistance. In this work, NP-ph/BA-ph blends and polymers were prepared. Copolymerization behaviors and processability of NP-ph/BA-ph were investigated and discussed. In addition, the effect of various contents of active diluent NP-ph on the polymerization rate and degree of the NP-
ph/BA-ph systems has also been monitored by Differential scanning calorimetry (DSC) and dynamic rheological analysis. Moreover, the thermal mechanical properties and thermal stabilities of NP-ph/BAph polymers were also investigated and discussed.

\section{Experimental}

\subsection{Materials}

P-nonylphenoxy (p-NP) (99\%), N, N-dimethylformamide (DMF) (99\%), potash $\left(\mathrm{K}_{2} \mathrm{CO}_{3}\right)(99 \%)$, 4nitrophthhalonitrile (Nph) (99\%), were purchased from Kelong Reagent Co. Ltd., Chengdu, China. All the chemicals and reagents were used without further purification. Phthalonitrile containing benzoxazine (BA-ph) was synthesized and purified according to the procedure reported before [7].

\subsection{Preparation of the NP-ph monomer}

$33 \mathrm{~g}$ of p-nonylphenoxy and $60 \mathrm{~mL}$ DMF were added to a $250 \mathrm{~mL}$ three necks round bottle flask equipped with a mechanical stirrer and refluxing condenser, the mixtures were heated at $60^{\circ} \mathrm{C}$ for few minutes to be dissolved sufficiently, then the $\mathrm{K}_{2} \mathrm{CO}_{3}$ was added to the solution and the temperature was kept at $60^{\circ} \mathrm{C}$ with vigorous stirring for $5 \mathrm{~h}$. After that, 4-nitrophthalonitrile ( $\mathrm{Nph}$ ) was added to the light pink mixtures and continued stirring for another $3 \mathrm{~h}$. Finally, an orange solution was obtained. Then the solution was poured into water to precipitate the NP-ph monomer with vigorously stirring, the products were separated and washed several times by distilled water and then dried at $100^{\circ} \mathrm{C}$ overnight.

\subsection{Preparation of NP-ph/BA-ph blends}

The NP-ph/BA-ph thermosetting copolymers with different ratios (NP-ph content: 10, 20, 30, and $40 \mathrm{wt} \%$ ) were prepared by melt blending at $140^{\circ} \mathrm{C}$ for $20 \mathrm{~min}$.

\subsection{Preparation of the NP-ph/BA-ph polymers}

Firstly, polytetrafluoroethylene mold with cavity dimensions $50 \mathrm{~mm} \times 10 \mathrm{~mm} \times 3 \mathrm{~mm}$ was preheated at $160^{\circ} \mathrm{C}$ for $2 \mathrm{~h}$. Then, the NP-ph/BA-ph blend was molten at $140^{\circ} \mathrm{C}$ for $20 \mathrm{~min}$ and the viscous melt was poured into the preheated polytetrafluoroethylene mold to undergo the curing procedures. In accordance with the results of DSC, the onset temperature of the curing reaction was $200^{\circ} \mathrm{C}$ and the double peaks of exothermic reaction were about 
240 and $280^{\circ} \mathrm{C}$. As well known, explosive curing reaction would lead to large numbers of internal defects. Combination of the results of dynamic rheological analysis, $T=180^{\circ} \mathrm{C}$ was chosen as a moderate onset temperature of polymerization. $160^{\circ} \mathrm{C}$ was selected to make sure that the blend could be molten well and it was enough to eliminate the air bubbles in the viscous melt resin. In sum, the curing procedure was selected as follows: $160^{\circ} \mathrm{C}(4 \mathrm{~h}), 180^{\circ} \mathrm{C}$ (4 h), $200^{\circ} \mathrm{C}(4 \mathrm{~h}), 240^{\circ} \mathrm{C}(2 \mathrm{~h}), 280^{\circ} \mathrm{C}(2 \mathrm{~h})$. The cured NP-ph/BA-ph polymers were sanded to a thickness of $2 \mathrm{~mm}$ for the Dynamic mechanical measurements (DMA). Also, the cured NP-ph/BA-ph polymers were physically pulverized under ambient conditions for thermal gravimetric analysis (TGA).

\subsection{Characterizations}

Nuclear magnetic resonance $\left({ }^{1} \mathrm{H}-\mathrm{NMR}\right)$ spectra were taken on a AV400 nuclear magnetic resonance spectrometer with a proton frequency of $300 \mathrm{MHz}$ and the solvent was $\mathrm{CDCl}_{3}$, Bruker, Germany. Fourier Transform Infrared (FTIR) spectra were recorded with FTIR8400S Fourier Transform Infrared spectrometer in $\mathrm{KBr}$ pellets between 4000 and $500 \mathrm{~cm}^{-1}$ in air, Shimadzu, Japan. Differential scanning calorimetric (DSC) analysis was performed by Modulated DSC-Q100 at a heating rate of $10^{\circ} \mathrm{C} / \mathrm{min}$ and a nitrogen flow rate of $50 \mathrm{~mL} / \mathrm{min}$, TA Instruments, USA. The DSC testing of NP-ph and BA-ph monomer was performed by heating the samples from 50 to $350^{\circ} \mathrm{C}$, while, the NP-ph/BA-ph blending was heater from 100 to $350^{\circ} \mathrm{C}$. Viscosity studies and curing process of the blends were conducted using Rheometer AR-G2 with a heating rate of $5^{\circ} \mathrm{C} / \mathrm{min}$ and a frequency of $1 \mathrm{~Hz}$ from 50 to $300^{\circ} \mathrm{C}$ in air, TA Instruments, USA. The samples $(0.5-1 \mathrm{~g})$ were melted between $25 \mathrm{~mm}$ diameter parallel plates with the gap of $1000 \mu \mathrm{m}$ and shear rate of $1 \mathrm{~Hz}$. The isothermal tests of dynamic rheological analysis were performed at 160, 180 and $200^{\circ} \mathrm{C}$, respectively, with a frequency of $1 \mathrm{~Hz}$ and shear rate of $1 \mathrm{~Hz}$. Dynamic mechanical analysis (DMA) in a three-point-blending mode was per-
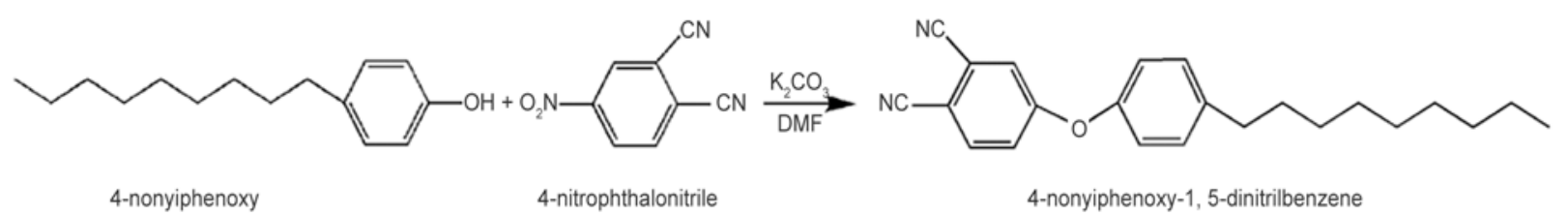

Figure 1. Synthesis of the NP-ph monomer formed on QDMA-800 dynamic mechanical analyzer to determine the glass transition temperature $\left(T_{\mathrm{g}}\right)$, TA Instruments, USA. The storage modulus and tan delta were investigated at a frequency of $1 \mathrm{~Hz}$ and amplitude of $20 \mu \mathrm{m}$, and the samples (dimensions $30 \mathrm{~mm} \times 10 \mathrm{~mm} \times 2 \mathrm{~mm}$ ) were heated from 50 to $400^{\circ} \mathrm{C}$ at a temperature ramp of $3^{\circ} \mathrm{C} / \mathrm{min}$. Thermogravimetry (TGA) and Differential presentation of integral TGA (DTA) was performed on a TGA Q50 with a heating rate of $20^{\circ} \mathrm{C} / \mathrm{min}$ (under nitrogen or air) and a purge of $40 \mathrm{~mL} / \mathrm{min}$ from 100 to $800^{\circ} \mathrm{C}$, TA Instruments, USA.

\section{Results and discussion \\ 3.1. Synthesis and characterization of NP-ph monomer}

The NP-ph monomer has been synthesized via substitution reaction of 4-nitrophthalonitrile and pnonylphenoxy at the presence of $\mathrm{K}_{2} \mathrm{CO}_{3}$ in the $\mathrm{N}$, $\mathrm{N}$-dimethylformamide (DMF) solvent (Figure 1). The assumed reaction sequence is depicted in Figure 2. The monomer structures were characterized by ${ }^{1} \mathrm{H}-\mathrm{NMR}$ and FTIR spectroscopies. The relevant data are listed as follows.

${ }^{1} \mathrm{H}-\mathrm{NMR}\left(300 \mathrm{MHz}, \mathrm{CDCl}_{3}-\mathrm{d} 6, \delta \mathrm{ppm}\right): 0.96(\mathrm{t}$, $3 \mathrm{H}, \mathrm{CH} 3), 1.29-1.62(\mathrm{~m}, 14 \mathrm{H},-\mathrm{CH} 2-), 2.55(\mathrm{t}, 2 \mathrm{H}$, $\mathrm{Ar}-\mathrm{CH} 2), 7.08$ (t, 2H, Ar-H), 6.87 (d, 2H, Ar-H), 7.35 (s, 1H, Ar-H), 7.38 (d, 1H, Ar-H), 7.65 (d, 1H, Ar-H).

FTIR (liquid state, $\mathrm{cm}^{-1}$ ): 3250 to $2750 \mathrm{~cm}^{-1}(-\mathrm{C}-\mathrm{H}$ stretching vibrations of the alkyl), $2230 \mathrm{~cm}^{-1}$ (-CN), $1230 \mathrm{~cm}^{-1}$ (stretch, Ar-O-Ar), $1490 \mathrm{~cm}^{-1}$ (1,2 and 4 substitution of benzene ring).

${ }^{1} \mathrm{H}-\mathrm{NMR}$ spectrum was shown in Figure 3 and FTIR spectrum was depicted in Figure 4. In ${ }^{1} \mathrm{H}-\mathrm{NMR}$ spectrum, the prominent resonances at $0.866-$ $2.66 \mathrm{ppm}$ in the aliphatic frequency corresponded to the hydrogen in the long hydrocarbyl segment. The prominent resonances at $6.76-7.71 \mathrm{ppm}$ were consistent with the hydrogens in the benzene ring. The data were found to be in good agreement with the proposed structures. 


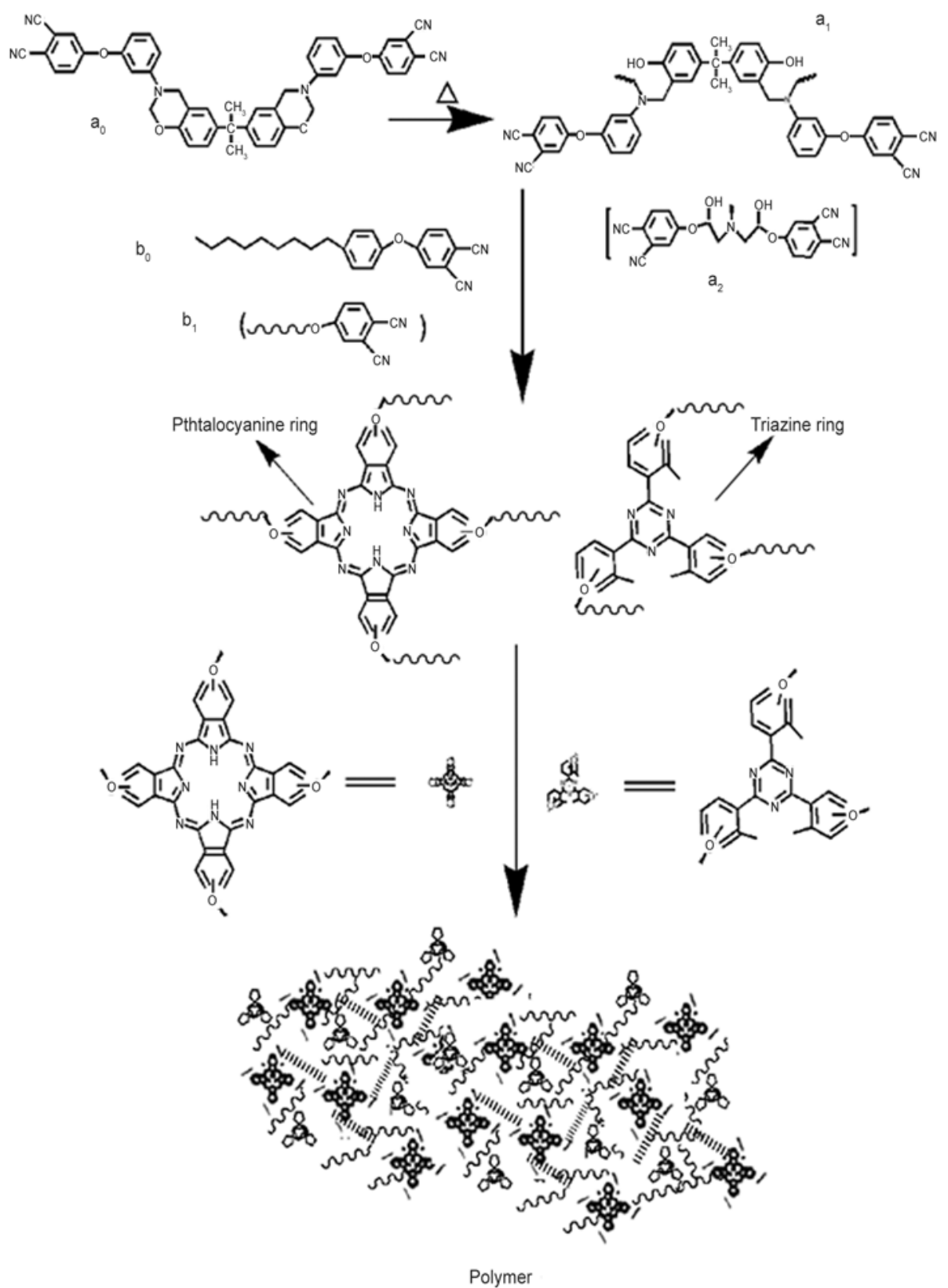

Figure 2. Preparation of NP-ph/BA-ph copolymers: $a_{0}$ ) BA-ph monomer, $a_{1}$ ) BA-ph monomer with ring-opening of oxazine, $a_{2}$ ) simplification of $a_{1}, b_{0}$ ) NP-ph monomer, $b_{1}$ ) simplification of $b_{0}$

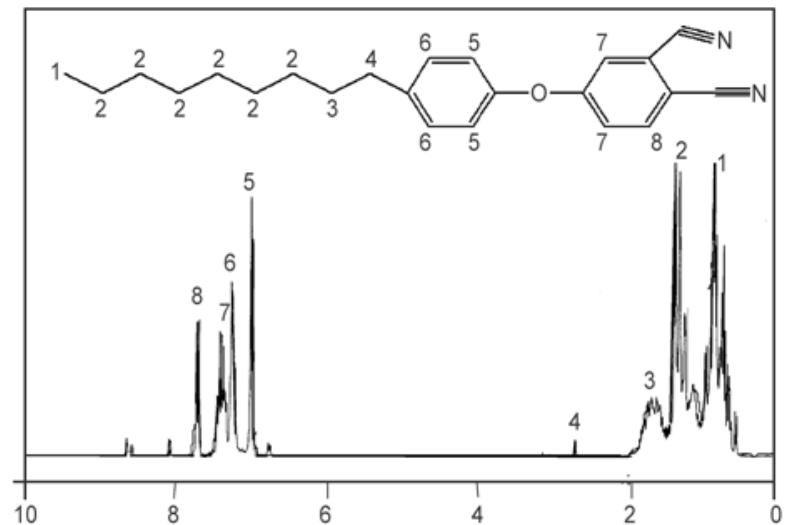

Figure 3. The ${ }^{1} \mathrm{H}-\mathrm{NMR}$ spectrum of NP-ph in $\mathrm{CDCl}_{3}$
The FTIR spectrum for NP-ph monomer was discussed in the range from 4000 to $500 \mathrm{~cm}^{-1}$, as shown in Figure 4. The absorption peaks at round $1230 \mathrm{~cm}^{-1}$ represented the antisymmetry stretching vibrations of diphenyl ether indicated the interaction between p-nonylphenoxy and 4-nitrophthhalonitrile. The intensive absorption peak at $2230 \mathrm{~cm}^{-1}$ was assigned to the stretching vibrations of cyano groups $(-\mathrm{CN})$ [22]. The absorption band of the $\mathrm{C}-\mathrm{H}$ stretching vibration of saturated hydrocarbon was observed in the range of 2750 and $3000 \mathrm{~cm}^{-1}$. While, the absorption band of aromatic hydrocarbon was observed above $3000 \mathrm{~cm}^{-1}$ as the shoulder of the band in the 


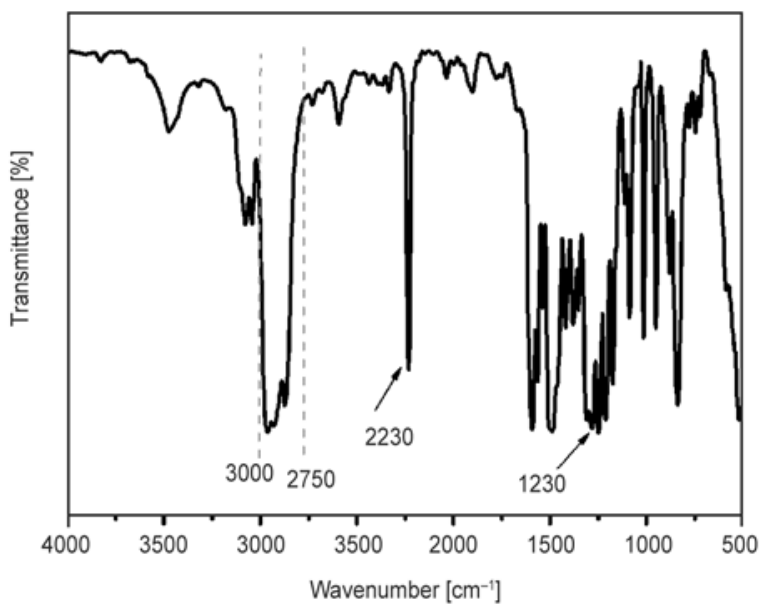

Figure 4. The FTIR spectrum of NP-ph

range from 2750 to $3000 \mathrm{~cm}^{-1}$ corresponding to the saturated hydrocarbon. The characteristic absorption bands in Figure 4 demonstrated that the phthalonitrile containing flexible chains have been obtained.

\subsection{Self-promoted curing behaviors on NP-ph/BA-ph copolymers}

Figure 5 showed the DSC thermograms in the temperature range from 50 to $350^{\circ} \mathrm{C}$ at the heating rate of $10^{\circ} \mathrm{C} / \mathrm{min}$ of BA-ph and NP-ph resins, respectively. The curve showed the curing exotherm of the BA-ph monomer exhibited two characteristic exothermic peaks: a peak maximum of about $220^{\circ} \mathrm{C}$ and the other about $260^{\circ} \mathrm{C}$, which was characteristic of the thermal curability of the resin $[7,8]$. On the contrary, the NP-ph resin showed no sign of a curing reaction in this temperature range without added initiators or catalysts. As was well known, the polymerization of the neat phthalonitrile monomers was extremely sluggish and this procedure needed sev-

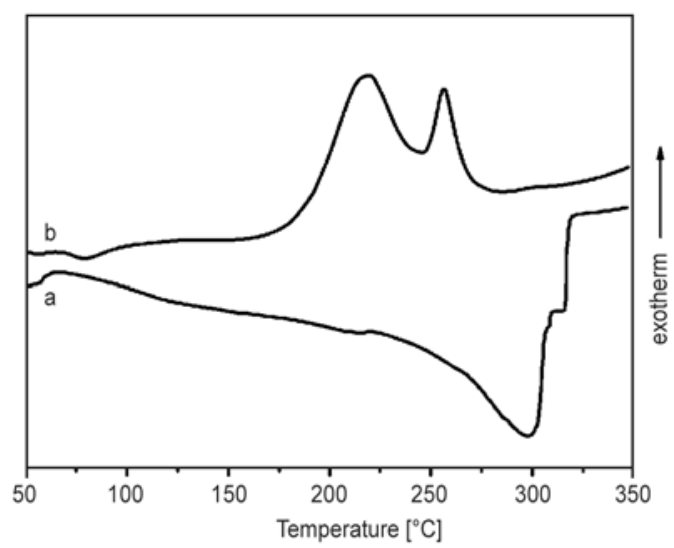

Figure 5. The DSC curves of (a) BA-ph monomer and (b) NP-ph monomer
Table 1. Thermal properties and gelation time at $180^{\circ}$ of NP-ph/BA-ph blends

\begin{tabular}{|c|c|c|c|c|c|}
\hline Samples & $\begin{array}{c}\mathbf{T}_{\text {top1 }} \\
{\left[{ }^{\circ} \mathbf{C}\right]}\end{array}$ & $\begin{array}{c}\Delta \mathbf{H}_{\text {curing }} \\
{\left[\mathbf{J}^{\left.-g^{-1}\right]}\right.}\end{array}$ & $\begin{array}{c}\mathbf{T}_{\text {top2 }} \\
{\left[{ }^{\circ} \mathbf{C}\right]}\end{array}$ & $\begin{array}{c}\Delta \mathbf{H}_{\text {curing }} \\
{\left[\mathbf{J}^{\left.-g^{-1}\right]}\right.}\end{array}$ & $\begin{array}{c}\text { Gelation time } \\
\text { at } \mathbf{1 8 0}^{\circ} \mathbf{C} \\
{[\mathbf{m i n}]}\end{array}$ \\
\hline $10 \%$ & 225.9 & 131.0 & 262.7 & 53.6 & 23 \\
\hline $20 \%$ & 231.5 & 106.4 & 266.1 & 79.5 & 29 \\
\hline $30 \%$ & 235.7 & 75.6 & 270.0 & 77.8 & 37 \\
\hline $40 \%$ & 240.5 & 102.5 & 273.3 & 63.2 & 48 \\
\hline
\end{tabular}

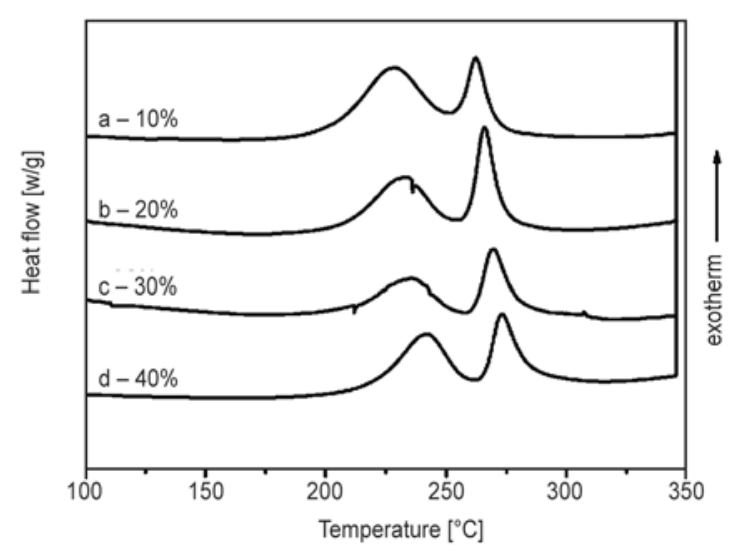

Figure 6. The DSC curves of NP-ph/BA-ph blends with various content of NP-ph (a) $10 \%$, (b) $20 \%$, (c) $30 \%$ and (d) $40 \%$

eral days to obtain stable polymers [7, 23, 24]. Thus, in the case of the NP-ph resin, no self-promoted polymerization has occurred in this temperature range. Meanwhile, an endothermic peak at about $300^{\circ} \mathrm{C}$ has been observed which may be as a result of evaporation of the monomer.

The self-promoted curing behaviors of the NP-ph/ BA-ph blends were studied by DSC (Figure 6) and the main results were listed in Table 1. In the curves shown in Figure 6, the retardation of the polymerization reaction of BA-ph resin has been observed as a weak shift of the exothermic peaks to higher temperature. The degree of the retardation increases with increasing amounts of NP-ph resin. This was because the NP-ph component in the system acted as a diluent, resulting in the retardation of the polymerization of BA-ph resin. The curing reaction would occur preferentially at around $220^{\circ} \mathrm{C}$ and the oxazine ring-opening polymerization produced Mannich bridge $\left(-\mathrm{CH}_{2}-\mathrm{NR}-\mathrm{CH}_{2}-\right)$ with phenolic hydroxyl functional groups (Figure 2). The polymerization among BA-ph monomers was predominant in the temperature range from $210-240^{\circ} \mathrm{C}[9,10]$. Then the free phenolic hydroxyls with active hydrogen generated from the ring-opening reaction of BA-ph at elevated temperatures $\left(265^{\circ} \mathrm{C}\right)$ may promote the 
polymerization of cyano groups of BA-ph and NPph. That was, at proper temperature $\left(210-240^{\circ} \mathrm{C}\right)$, ring-opening of benzaoxazine rings took place and a certain amount of active hydroxyls was generated. On the one hand, the oxazine ring-opening polymerization occurred to produce Mannich bridge structures. On the other hand, in the presence of active hydrogen, cyano groups were catalyzed to become isoindole rings intermediates, and then immediately transited to phtahalocyanine and triazine rings with excess cyano groups. Continuously, the triazine and phthalocyanine rings formed between BA-ph and NP-ph resin. Large amounts of rigid groups would be entrapped into and twined by the flexible chains in the polymer matrices (Figure 2) $[8,25,26]$.

\subsection{Structures of NP-ph/BA-ph blends and polymers}

The structures of NP-ph/BA-ph blends and polymers with 20 and $40 \mathrm{wt} \% \mathrm{NP}-\mathrm{ph}$ have been confirmed by FTIR spectra shown in Figure 7 and Figure 8 . Figure 7 (a) and (b) curves showed the structure of the NP-ph/BA-ph blends with 20 and $40 \%$ NP-ph, respectively. It can be seen that the absorption band at around $956 \mathrm{~cm}^{-1}$ contributed to the trisubstituted benzene ring attached with oxazine ring, confirmed the existence of oxazine rings. The intense characteristic absorption band of cyano groups at $2230 \mathrm{~cm}^{-1}$ indicated that the polymerization of cyano groups hardly proceeded or did not occur at all. Meanwhile, the absorption band at $1493 \mathrm{~cm}^{-1}$, corresponding to the in-plane carbon-carbon stretching of the trisubstituted benzene ring, evidently indicated that the polymerization of the NP-ph/BA-ph blend

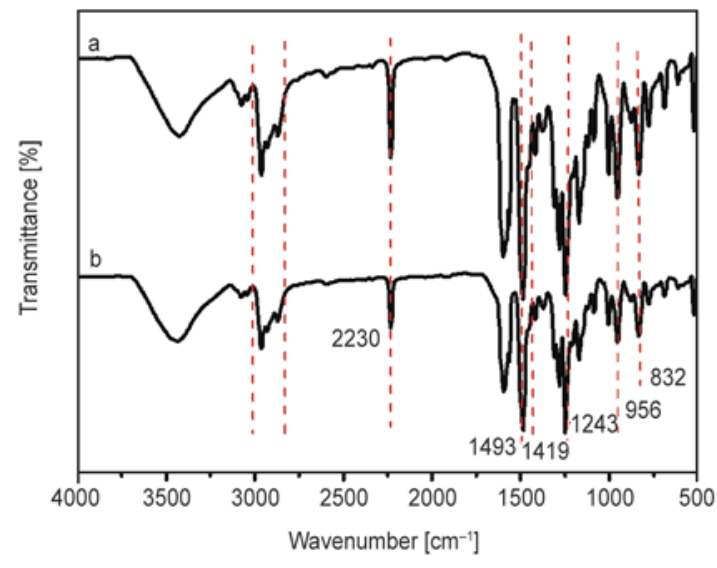

Figure 7. The FTIR spectra of NP-ph/BA-ph blends with various content of NP-ph (a) 20\% and (b) $40 \%$

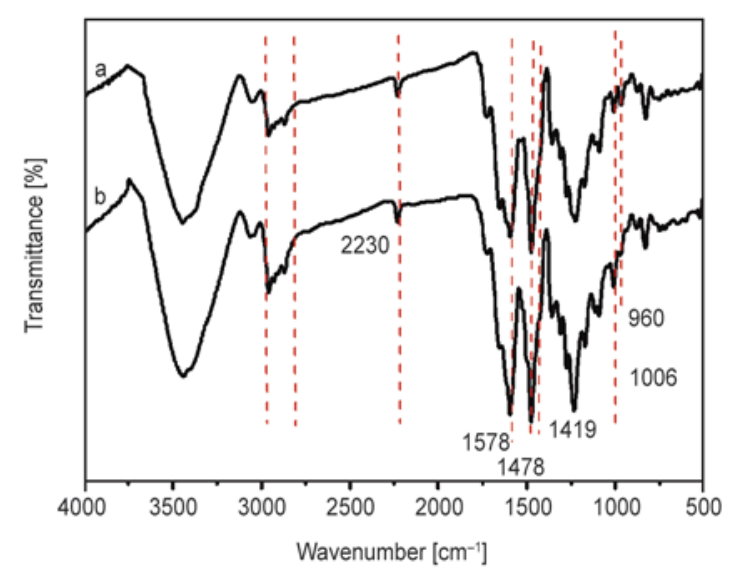

Figure 8. The FTIR spectra of NP-ph/BA-ph polymers with various content of NP-ph (a) $20 \%$ and (b) $40 \%$

did not occur during melt blending. Additionally, the characteristic absorption bands of NP-ph were observed in the NP-ph/BA-ph blend in Figure 7.

In comparison with the characteristic absorption bands shown in Figure 7, the intensity of the characteristic bands of benzoxazine at $\sim 956 \mathrm{~cm}^{-1}$ shown in Figure 8 reduced significantly, indicating that the benzoxazine has been involved to a great extent in the polymerization. The characteristic absorption band at $2230 \mathrm{~cm}^{-1}$ significantly decreased, new absorption bands at 1006 and $1578 \mathrm{~cm}^{-1}$ were observed which indicated the formation of phthalocyanine and triazine rings among cyano groups [7, 22]. The band at $1493 \mathrm{~cm}^{-1}$ has been shifted to $1478 \mathrm{~cm}^{-1}$, which corresponds the in-plane carboncarbon stretching of the tetrasubstituted benzene ring, indicating that the methylene bridges formed in the free ortho positions of the phenolic structures $[25,26]$. In comparison with that shown in Figure 7 , the formation of methylene bridges, phthalocyanine rings and triazine rings demonstrated that the copolymerization of NP-ph and BA-ph has occurred to a great extent.

\subsection{Processability of NP-ph/BA-ph blends}

The complex viscosity $\left(\eta^{*}\right)$ of NP-ph/BA-ph blends as a function of temperature from 50 to $300^{\circ} \mathrm{C}$ were shown in Figure 9. It can be seen that the $\eta^{*}$ of NP$\mathrm{ph} / \mathrm{BA}-\mathrm{ph}$ copolymers diminished gradually before $130^{\circ} \mathrm{C}$. The minimum of the $\eta^{*}$ was about $0.75 \mathrm{~Pa} \cdot \mathrm{s}$ at $150^{\circ} \mathrm{C}$ for the blend with $20 \% \mathrm{NP}-\mathrm{ph}$. At around $160^{\circ} \mathrm{C}$, there was a slight increase of $\eta^{*}$ and a rapid increase of $\eta^{*}$ was observed at $180-210^{\circ} \mathrm{C}$ for all of the NP-ph/BA-ph blends. Moreover, the sharp increase of $\eta^{*}$ was observed at higher temperatures with increasing the amount of NP-ph resin in the 


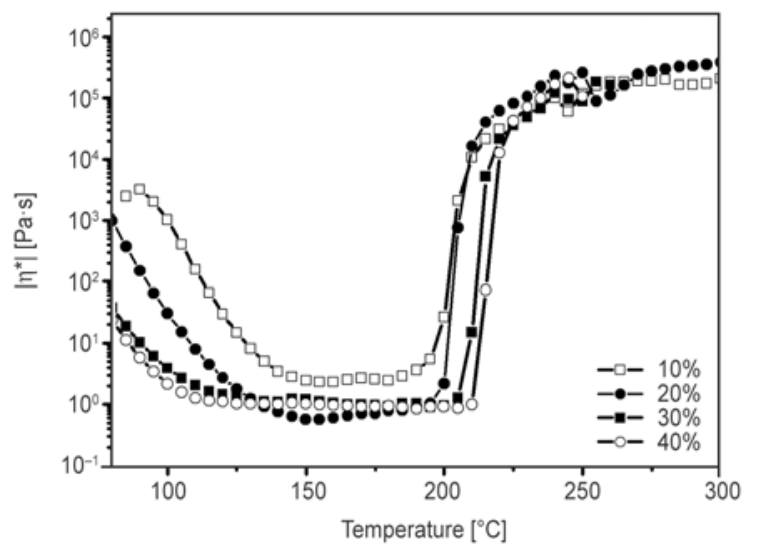

Figure 9. Complex viscosity curve as a function of temperature for NP-ph/BA-ph blends

blends. For the blend with $40 \%$ NP-ph, a rapid increase of $\eta^{*}$ was observed at $210^{\circ} \mathrm{C}$, indicating that the polymerization was delayed with increasing the amount of NP-ph, in good agreement with DSC results in Figure 4.

To further determine the processing temperature and time for NP-ph/BA-ph copolymers, the $\eta^{*}$ change of the NP-ph/BA-ph copolymer with $20 \%$ NP-ph was measured as a function of time at various temperatures, shown in Figure 10. It can be seen that the $\eta^{*}$ at different temperatures were relatively low and stable before the proper curing reaction started. However, after the curing reaction started, the $\eta^{*}$ increased dramatically. Nevertheless, the time for dramatic $\eta^{*}$ increase was varied with the different temperatures. Namely, the $\eta^{*}$ increase of NP-ph/ BA-ph copolymer at $160^{\circ} \mathrm{C}$ took a very long time (100 min), indicating that the reaction was carried out slowly. Quite the opposite, the $\eta^{*}$ increase of NP$\mathrm{ph} / \mathrm{BA}-\mathrm{ph}$ copolymers at $200^{\circ} \mathrm{C}$ took a rather short time, revealing that curing reaction was carried out

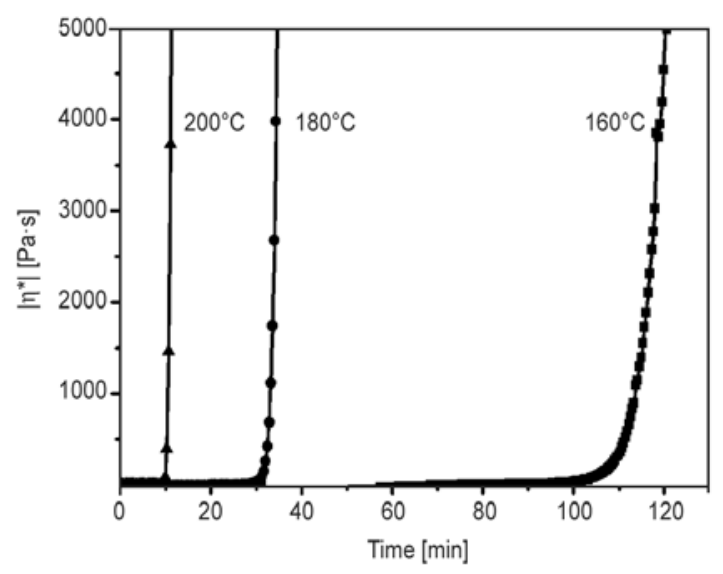

Figure 10. Complex viscosity as a function of time for the $20 \%$ NP-ph/BA-ph blends at various temperatures very fast. Thus, $180^{\circ} \mathrm{C}$ was a proper processing temperature for NP-ph/BA-ph copolymers. On the one hand, these results manifested that the $\eta *$ of the NP$\mathrm{ph} / \mathrm{BA}-\mathrm{ph}$ copolymer processed faster with increasing the processing temperature. On the other hand, these results revealed that processing temperature could accelerate the copolymerization reaction of NP-ph/BA-ph. From Figure 10, the processing time and polymerization rate of NP-ph/BA-ph system could be easily controlled by varying the processing temperature and the optical processing temperature for NP-ph/BA-ph copolymers was about $180^{\circ} \mathrm{C}$.

Thus, $180^{\circ} \mathrm{C}$ was chosen to investigate the effect of NP-ph content on the processability of NP-ph/BA-ph copolymers, as shown in Figure 11. It can be seen that all of the NP-ph/BA-ph copolymers exhibited relatively low initial $\eta^{*}$ and the initial $\eta^{*}$ of NP-ph/ BA-ph copolymers decreased with increasing the content of NP-ph. Generally, the low initial $\eta^{*}$ can offer convenience for processing such as fully mixing and removal of air bubbles, which was beneficial to practical operations and the final properties of products used in the field of RTM. Figure 11 also showed that with more NP-ph content, the time for cure reaction of NP-ph/BA-ph copolymers increased significantly, indicating that the NP-ph would retard the polymerization reaction rate of $\mathrm{BA}-\mathrm{ph}$. This may be due to that the sluggish NP-ph resin affected the generation, activity or redistribution of active hydroxyl generated from the ring-opening of benzoxazine rings, resulting in delaying the polymerization of cyano groups in the system. From these results, it was clear that NP-ph/BA-ph copolymer at processing temperature of $180^{\circ} \mathrm{C}$ exhibited good processing advantages due to the low initial $\eta^{*}$ and appro-

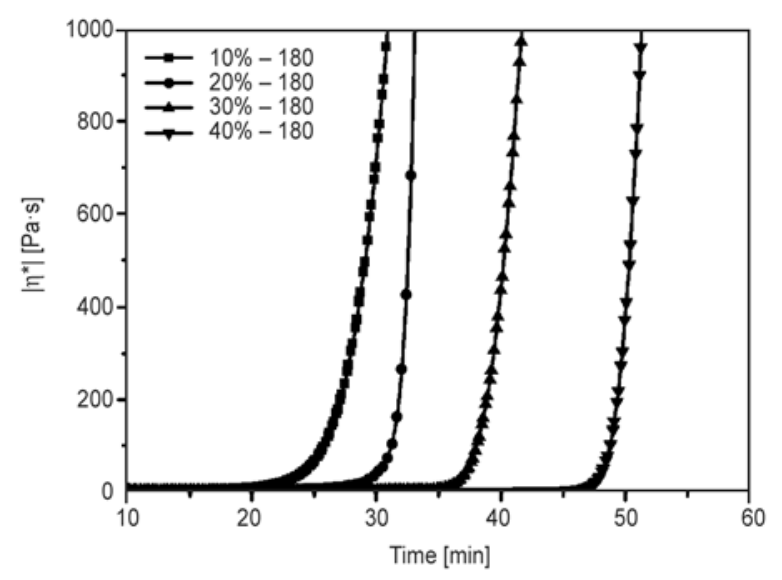

Figure 11. Complex viscosity as a function of time at $180^{\circ} \mathrm{C}$ for various NP-ph/BA-ph blends 
priate processing temperature, while the processability of NP-ph/BA-ph copolymers could be varied by the amount of NP-ph. Additionally, based on the principle of classical rheological theory, the gelation time was determined from the crossover point of the storage modulus $\left(G^{\prime}\right)$ and the loss modulus $\left(G^{\prime \prime}\right)$. The time of gel-point was collected in Table 1 which was distinguished from that of BA-ph [8]. The proper processing time resulting from the presence of NP-ph was in favor for industrial applications.

\subsection{Dynamic mechanical properties of NP-ph/BA-ph polymers}

In the previous parts, copolymerizing behaviors and processability of NP-ph/BA-ph copolymers were investigated. These investigations can provide us effective molding procedures to prepare NP-ph/ BA-ph polymers. Dynamic mechanical studies were conducted to evaluate the changes in the sample modulus as a function of temperature and determinate the $T_{\mathrm{g}}$ of the polymers. From these studies, storage modulus and tan delta plots generated on NP-ph/BA-ph polymers versus temperature were presented in Figure 12 and 13, respectively, and the results of $T_{\mathrm{g}}$ were exhibited in Table 2. In Figure 12, the modulus for NP-ph/BA-ph with 20\% NP-ph changed from 3650 to $10 \mathrm{MPa}$ when heated from 50 to $400^{\circ} \mathrm{C}$. For all of the samples, large modulus changes were observed after $300^{\circ} \mathrm{C}$. The data showed that the extent of the modulus changes decreased as the NP-ph content increased. However, the decrease for sample with $10 \% \mathrm{NP}$-ph may be the result of the pinholes in the sample pieces. The decrease in the

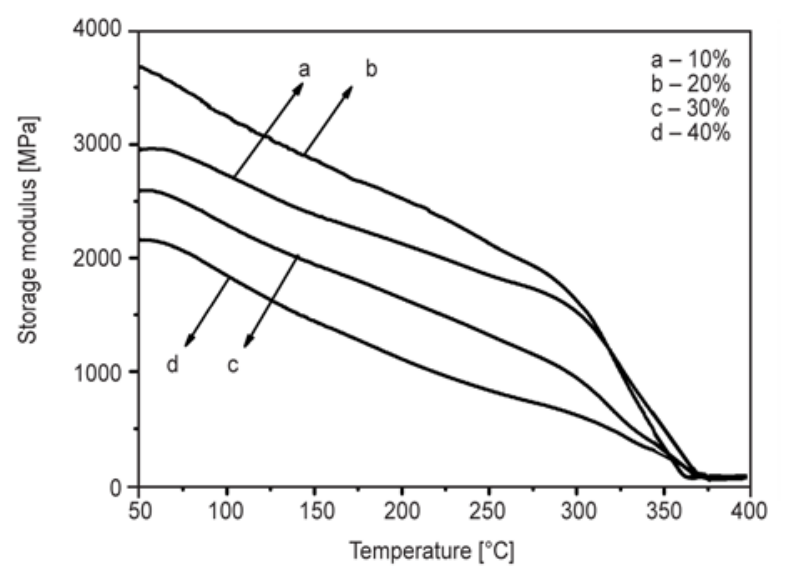

Figure 12. Storage modulus $\left(G^{\prime}\right)$ as a function of temperature for various NP-ph/BA-ph polymers heated in nitrogen
Table 2. Glass transition temperatures and thermal and thermo-oxidative stabilities of NP-ph/BA-ph polymers

\begin{tabular}{|c|c|c|c|c|c|c|c|}
\hline \multirow{3}{*}{ Samples } & \multicolumn{4}{|c|}{ Nitrogen } & \multicolumn{3}{c|}{ Air } \\
\cline { 2 - 8 } & $\begin{array}{c}\mathbf{T}_{\mathbf{g}} \\
{\left[{ }^{\circ} \mathbf{C}\right]}\end{array}$ & $\begin{array}{c}\mathbf{T}_{\mathbf{5} \%} \\
{\left[{ }^{\circ} \mathbf{C}\right]}\end{array}$ & $\begin{array}{c}\mathbf{T}_{10} \% \\
{\left[{ }^{\circ} \mathbf{C}\right]}\end{array}$ & $\begin{array}{c}\text { Yield } \\
\text { char }\end{array}$ & $\begin{array}{c}\mathbf{T}_{\mathbf{5} \%} \\
{\left[{ }^{\circ} \mathbf{C}\right]}\end{array}$ & $\begin{array}{c}\mathbf{T}_{\mathbf{1 0}} \% \\
{\left[{ }^{\circ} \mathbf{C}\right]}\end{array}$ & $\begin{array}{c}\text { Yield } \\
\text { char }\end{array}$ \\
\hline $10 \%$ & 371 & 437 & 483 & $72.7 \%$ & 438 & 477 & $27.2 \%$ \\
\hline $20 \%$ & 368 & 425 & 478 & $71.3 \%$ & 435 & 473 & $12.4 \%$ \\
\hline $30 \%$ & 366 & 422 & 469 & $69.8 \%$ & 426 & 473 & $4.0 \%$ \\
\hline $40 \%$ & 365 & 416 & 448 & $64.3 \%$ & 414 & 465 & $3.0 \%$ \\
\hline
\end{tabular}

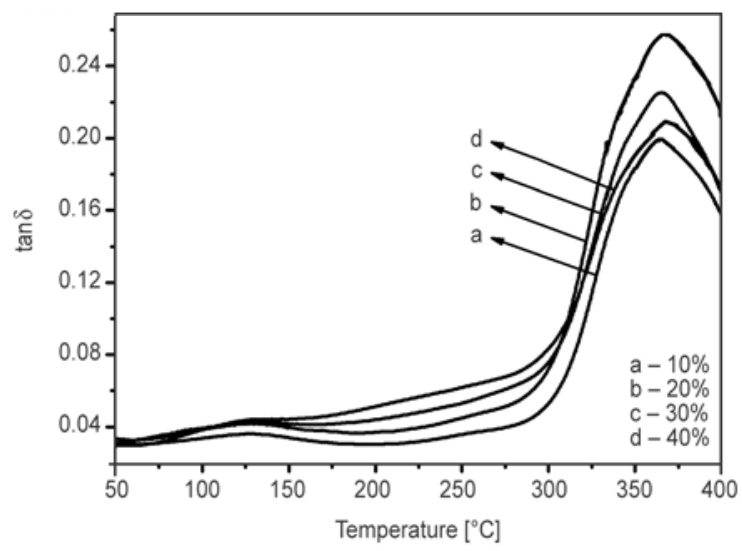

Figure 13. Damping factor $(\tan \delta)$ as a function of temperature for various NP-ph/BA-ph polymers heated in nitrogen

storage modulus was attributed to the stress relaxation of NP-ph/BA-ph copolymers.

Thus, the $T \mathrm{~g}$ was obtained from the maximum of $\tan \delta$ in a plot of $\tan$ delta versus temperature. As noted in Figure 13, one or two relaxation peaks were observed in each plot. The $\tan \delta$ peaks $\left(100-150^{\circ} \mathrm{C}\right)$ of all the NP-ph/BA-ph polymers were attributed to NP-ph. On heating to $400^{\circ} \mathrm{C}$, the $\tan \delta$ peaks of all the NP-ph/BA-ph polymers occurred at above $360^{\circ} \mathrm{C}$. Meanwhile, it can be seen that the tan delta peak shifted to lower temperatures as the NP-ph content increased. As was well known, the $T_{\mathrm{g}}$ of polymers depended on the rigidity of the molecular chains and the crosslinking degree [27-32]. It can be seen in Table 2 that the $T_{\mathrm{g}}$ of the samples were up to $360^{\circ} \mathrm{C}$, which were obviously superior to the traditional epoxy, phenolics and polybenzoxazines resin [28, 30-32]. The outstanding $T_{\mathrm{g}}$ was mainly attributed to the high crosslinking degree of ringopening polymerization of benzoxazine and heterocyclization of cyano groups in the NP-ph/BA-ph system. The polymerization of the active groups significantly increased the crosslinking degree and rigidity of the polymer, which greatly limited the motion of the molecular chains. With increasing the 
content of NP-ph, the amount of flexible alkyl chins increased and then decreased the rigidity of the polymer to some extent, eventually resulting to the reduction of $T_{\mathrm{g}}$.

\subsection{Thermal stabilities of NP-ph/BA-ph polymers}

The thermal decomposition of the NP-ph/BA-ph polymers was also examined by TGA (Figure 14) both in inert (nitrogen) and air (20\% oxygen) environments at a heating rate of $20^{\circ} \mathrm{C} / \mathrm{min}$ and the main results were summarized in Table 2 , in which the temperatures at weight loss of $5 \%\left(T_{5 \%}\right), 10 \%\left(T_{10 \%}\right)$ and char yield at $800^{\circ} \mathrm{C}$ were displayed. For comparison, the thermal properties of BA-ph polymer have been provided in Table 2. Overall, all of the polymers exhibit a slow degradation in nitrogen environment beginning at about $420^{\circ} \mathrm{C}$ and extending to $800^{\circ} \mathrm{C}$. This slow degradation rate may be attributed to the high concentration of phthalocyanine rings and triazine rings in the network, which may protect against degradation even at these high temperatures. The $T_{5 \%}$ weight losses of the cured NP-

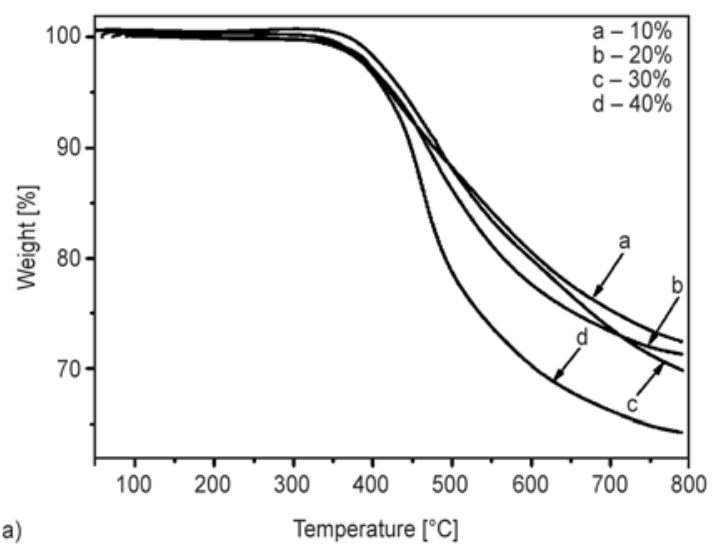

$\mathrm{ph} / \mathrm{BA}-\mathrm{ph}$ polymers in nitrogen atmosphere were in the range of $416-437^{\circ} \mathrm{C}$, and char yields at $800^{\circ} \mathrm{C}$ were in the range of $64-72 \%$. The results indicated that the thermal stabilities of NP-ph/BA-ph polymers in $\mathrm{N}_{2}$ atmosphere were weakly decreased by the increase of NP-ph content, which could be attributed to the relatively low thermal stabilities of NP-ph itself resulting from the long hydrocarbyl segments. The degradation profiles for these polymers were similar in air and nitrogen. In air atmosphere, $T_{5 \%} \mathrm{~S}$ were in the range of $414-438^{\circ} \mathrm{C}$ and char yields were in the range of $2.9-27.2 \%$. Under air atmosphere, the 5\% weight loss temperatures for the NP$\mathrm{ph} / \mathrm{BA}-\mathrm{ph}$ polymers were approximately equivalent to those observed under nitrogen atmosphere. This suggested that oxygen almost did not play a significant role on the $T_{5 \%}$ of NP-ph/BA-ph polymers. Nevertheless, the $60-75 \%$ chars remaining at $800^{\circ} \mathrm{C}$ was obviously higher than those of under atmospheric conditions, which related to the different degradation mechanisms and thermal properties according to the thermal history $[33,34]$. The differential presentation of integral TGA curves (DTA) was shown in Fig-

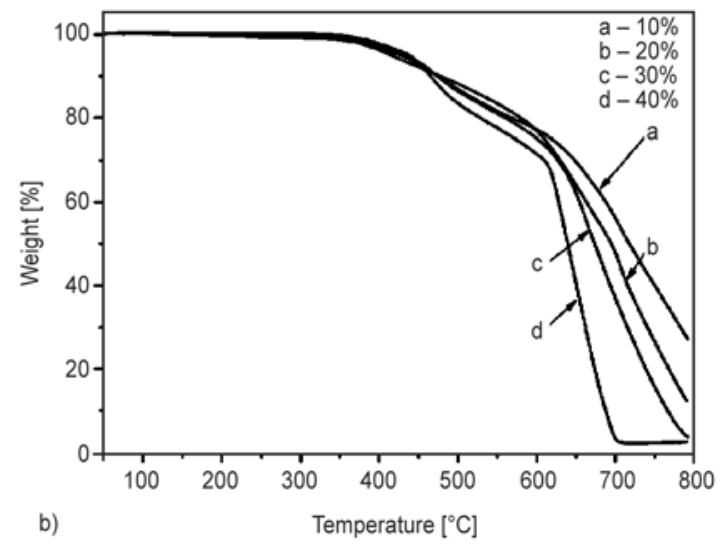

Figure 14. TGA curves of NP-ph/BA-ph composites (a) in nitrogen, (b) in air
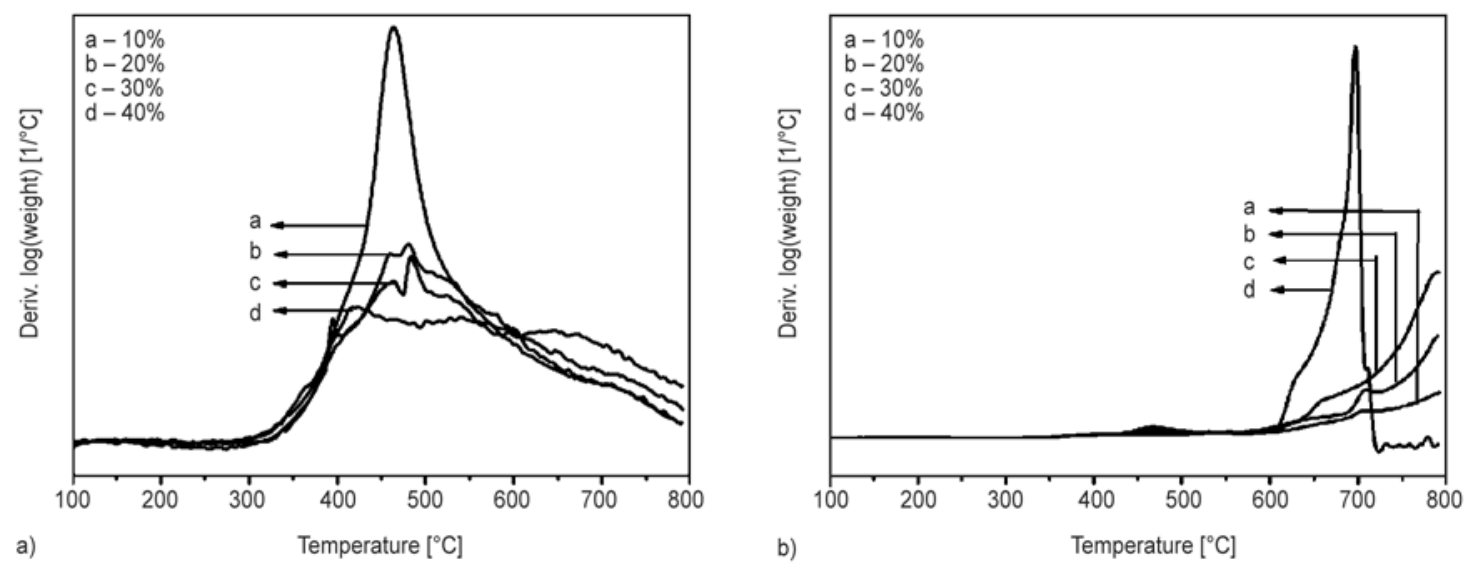

Figure 15. DTA curves of NP-ph/BA-ph composites (a) in nitrogen, (b) in air 
ure 15 to improve the interpretation of the doublestep character of thermal degradation. It could be seen in Figure 15a that a main degradation step was observed which started at around $350^{\circ} \mathrm{C}$ and reached the maximum at around $460^{\circ} \mathrm{C}$. However, in Figure $15 \mathrm{~b}$, the double-step thermal degradation was observed at around 470 and $680^{\circ} \mathrm{C}$, suggesting two major decomposition processes, which was obviously distinguished from the character of degradation in $\mathrm{N}_{2}$. In the presence of oxygen, bridging methylene and methyl groups were preferential to be thermaloxidatived and decomposed at around $400^{\circ} \mathrm{C}$. In addition to oxidative degradation, further thermal chain scission was characteristic at elevated temperatures $\left(>600^{\circ} \mathrm{C}\right)$. Nevertheless, in inert atmospheres, thermal chain scission, including bridging methylene and methyl groups, was the main thermal degradation process. Compared with other state-of-the-art thermosetting composites, the NP-ph/BA-ph exhibited excellent thermal and thermal-oxidative stabilities. The phthalonitrile-based composites or laminates, by comparison, showed as high $T_{5 \%}$ as NP-ph/BAph systems [34-37]. However, these composites have to be cured at elevated temperatures $\left(\right.$ over $350^{\circ} \mathrm{C}$ ) for a very long time ( $24 \mathrm{~h}$ or even more), which would be hard in the practical processing. The thermosetting polyimide-based composite laminates, on the other hand, were durable for a long time at $343^{\circ} \mathrm{C}$, but the high-temperature machining increased the difficulty of processing and limited their potential applications. To sum up, the excellent thermo-oxidative stabilities and high $T_{\mathrm{g}} \mathrm{s}$, together with the sound processing conditions could enable the NP-ph/BA-ph polymers to find uses in the fields of RTM and those under some practical critical circumstances with requirements of high wears and temperatures.

\section{Conclusions}

A novel kind of phthalonitrile containing flexible chains (NP-ph) has been successfully synthesized and investigated. Then, the low viscosity NP-ph resin has been incorporated into the BA-ph matrix to prepare NP-ph/BA-ph copolymers and polymers with various amount of NP-ph. The curing and rheological behaviors of the NP-ph/BA-ph copolymers were studied and the results indicated that the viscosity and processability can be tuned flexibly by varying the content of NP-ph, process temperature and time. The NP-ph/BA-ph polymers were obtained underwent the curing procedure mentioned above without any other curing agents. Results demonstrated that the NP-ph/BA-ph polymer exhibited outstanding glass transition temperature $\left(T_{\mathrm{g}}>360^{\circ} \mathrm{C}\right)$ and good thermal stability $\left(T_{5 \%}>420^{\circ} \mathrm{C}\right)$. Good processability and sound processing conditions, combined with the outstanding $T_{\mathrm{g}}$ as well as excellent thermal stabilities enable the as-prepared NP-ph/ BA-ph copolymers to find uses under some practical critical circumstances with requirements of high wears and temperatures.

\section{Acknowledgements}

The authors wish to thank for financial support of this work from the National Natural Science Foundation (No. 51173021) and ' 863 ' National Major Program of High Technology (2012AA03A212).

\section{References}

[1] Lundström T. S., Gebart B. R.: Influence from process parameters on void formation in resin transfer molding. Polymer Composites, 15, 25-33 (1994).

DOI: $10.1002 /$ pc. 750150105

[2] Trochu F., Gauvin R., Gao D-M.: Numerical analysis of the resin transfer molding process by the finite element method. Advances in Polymer Technology, 12, 329-342 (1993).

DOI: $10.1002 / \mathrm{adv} .1993 .060120401$

[3] Seemann W. H.: Plastic transfer molding techniques for the production of fiber reinforced plastic structures. U.S. Patent 4902215, USA (1990).

[4] Seemann W. H.: Plastic transfer molding apparatus for the production of fiber Plastic transfer molding apparatus for the production of fiber reinforced plastic structures. U.S. Patent 5052906, USA (1991).

[5] Seemann W. H.: Unitary vacuum bag for forming fiber reinforced composite articles. U.S. Patent 5316462 , USA (1994).

[6] Yan Y., Shi X., Liu J., Zhao T., Yu Y.: Thermosetting resin system based on novolak and bismaleimide for resin-transfer molding. Journal of Applied Polymer Science, 83, 1651-1657 (2002). DOI: $10.1002 /$ app. 10073

[7] Cao G. P., Chen W. J., Wei J. J., Li W. T., Liu X. B.: Synthesis and characterization of a novel bisphthalonitrile containing benzoxazine. Express Polymer Letters, 1, 512-518 (2007).

DOI: $10.3144 /$ expresspolymlett.2007.73

[8] Xu M., Yang X., Zhao R., Liu X.: Copolymerizing behavior and processability of benzoxazine/epoxy systems and their applications for glass fiber composite laminates. Journal of Applied Polymer Science, 128, 1176-1184 (2013).

DOI: 10.1002/app.38422 
[9] Xu M., Hu J., Zou X., Liu M., Dong S., Zou Y., Liu X.: Mechanical and thermal enhancements of benzoxazine-based GF composite laminated by in situ reaction with carboxyl functionalized CNTs. Journal of Applied Polymer Science, 129, 2629-2637 (2013). DOI: $10.1002 /$ app.38988

[10] Cid J. A., Wang Y-X., Ishida H.: Cationic polymerization of benzoxazine monomers by boron trifluoride complex. Polymers and Polymer Composites, 7, 409420 (1999).

[11] Wang Y-X., Ishida H.: Cationic ring-opening polymerization of benzoxazines. Polymer, 40, 4563-4570 (1999).

DOI: $10.1016 / \mathrm{S} 0032-3861(99) 00074-9$

[12] Iji M., Kiuchi Y.: Flame-retardant epoxy resin compounds containing novolac derivatives with aromatic compounds. Polymers for Advanced Technologies, 12, 393-406 (2001).

DOI: $10.1002 /$ pat.66

[13] Hergenrother P. M., Connell J. W., Smith J. G.: Phenylethynyl containing imide oligomers. Polymer, 41, 5073-5081 (2000).

DOI: $10.1016 / \mathrm{S} 0032-3861(99) 00569-8$

[14] Homrighausen C. L., Keller T. M.: Synthesis of hydroxy-terminated, oligomeric poly(silarylene disiloxane)s via rhodium-catalyzed dehydrogenative coupling and their use in the aminosilane-disilanol polymerization reaction. Journal of Polymer Science Part A: Polymer Chemistry, 40, 1334-1341 (2002). DOI: $10.1002 /$ pola. 10110

[15] Zuo F., Liu X.: Synthesis and curing behavior of a novel benzoxazine-based bisphthalonitrile monomer. Journal of Applied Polymer Science, 117, 1469-1475 (2010). DOI: $10.1002 /$ app.31978

[16] May C. A.,Tanaka G. Y.: Epoxy resin chemistry and technology. Marcel Dekker, New York (1973).

[17] Baur R. S.: Epoxy resin chemistry. American Chemical Society, Washington (1979).

[18] Potter W. G.: Epoxide resins. Springer, New York (1970).

[19] McAdams L. V., Gannon J. A.: Epoxy resins. in 'Encyclopedia of polymer science and engineering' (eds.: Mark H. F., Bikales N., Overberger C. G., Menges G., Kroschwitz J. I.) New York, Vol 6, 322-382 (1986).

[20] Xu Y., Hoa S. V.: Mechanical properties of carbon fiber reinforced epoxy/clay nanocomposites. Composites Science and Technology, 68, 854-861 (2008). DOI: 10.1016/j.compscitech.2007.08.013

[21] Bekyarova E.,Thostenson E. T., Yu A., Kim H., Gao J., Tang J., Hahn H. T., Chou T-W., Itkis M. E., Haddon R. C.: Multiscale carbon nanotube-carbon fiber reinforcement for advanced epoxy composites. Langmuir, 23, 3970-3974 (2007). DOI: $10.1021 / 1 \mathrm{a} 062743 \mathrm{p}$
[22] Guo H., Lei Y., Zhao X., Yang X., Zhao R., Liu X.: Curing behaviors and properties of novolac/bisphthalonitrile blends. Journal of Applied Polymer Science, 125, 649-656 (2012).

DOI: $10.1002 / a p p .36335$

[23] Zhang J., Liu X., Wen H., Xie M., Cai X.: Investigation of the properties of phthalocyanine resin containing bismaleimide groups. Polymer International, 42, 363-366 (1997).

DOI: 10.1002/(SICI)1097-0126(199704)42:4<363:: AID-PI711>3.0.CO;2-0

[24] Yang X. L., Liu X. B.: Study on curing reaction of 4aminophenoxyphthalonitrile/bisphthalonitrile. Chinese Chemical Letters, 21, 743-747 (2010).

DOI: 10.1016/j.cclet.2009.12.022

[25] Chen Z., Guo H., Tang H., Yang X., Xu M., Liu X.: Preparation and properties of bisphenol A-based bisphthalonitrile composite laminates. Journal of Applied Polymer Science, 129, 2621-2628 (2013).

DOI: $10.1002 / a p p .38986$

[26] Agag T., Takeichi T.: Novel benzoxazine monomers containing $p$-phenyl propargyl ether: Polymerization of monomers and properties of polybenzoxazines. Macromolecules, 34, 7257-7263 (2001).

DOI: $10.1021 / \mathrm{ma} 0107915$

[27] Chow T. S.: Molecular interpretation of the glass transition temperature of polymer-diluent systems. Macromolecules, 13, 362-364 (1980). DOI: $10.1021 / \mathrm{ma} 60074 \mathrm{a} 029$

[28] Hancock B. C., Zografi G.: The relationship between the glass transition temperature and the water content of amorphous pharmaceutical solids. Pharmaceutical Research, 11, 471-477 (1994).

DOI: 10.1023/A:1018941810744

[29] Forrest J. A., Dalnoki-Veress K., Stevens J. R., Dutcher J. R.: Effect of free surfaces on the glass transition temperature of thin polymer films. Physical Review Letters, 77, 2002-2005 (1996). DOI: 10.1103 /PhysRevLett.77.2002

[30] Forrest J. A., Dalnoki-Veress K., Dutcher J. R.: Interface and chain confinement effects on the glass transition temperature of thin polymer films. Physical Review E, 56, 5705-5716 (1997).

DOI: 10.1103/PhysRevE.56.5705

[31] Allaoui A., El Bounia N.: How carbon nanotubes affect the cure kinetics and glass transition temperature of their epoxy composites? - A review. Express Polymer Letters, 3, 588-594 (2009).

DOI: 10.3144 /expresspolymlett.2009.73

[32] Kimura H., Ohtsuka K., Matsumoto A.: Curing reaction of bisphenol-A based benzoxazine with cyanate ester resin and the properties of the cured thermosetting resin. Express Polymer Letters, 5, 1113-1122 (2011).

DOI: $10.3144 /$ expresspolymlett.2011.108 
[33] Sumner M. J., Sankarapandian M., McGrath J. E., Riffle J. S., Sorathia U.: Flame retardant novolac-bisphthalonitrile structural thermosets. Polymer, 43, 50695076 (2002).

DOI: $10.1016 / \mathrm{S} 0032-3861(02) 00354-3$

[34] Laskoski M., Dominguez D. D., Keller T. M.: Synthesis and properties of a bisphenol A based phthalonitrile resin. Journal of Polymer Science Part A: Polymer Chemistry, 43, 4136-4143 (2005).

DOI: $10.1002 /$ pola.20901

[35] Dominguez D. D., Jones H. N., Keller T. M.: The effect of curing additive on the mechanical properties of phthalonitrile-carbon fiber composites. Polymer Composites, 25, 554-561 (2004).

DOI: $10.1002 /$ pc.20049
[36] Dominguez D. D., Keller T. M.: Properties of phthalonitrile monomer blends and thermosetting phthalonitrile copolymers. Polymer, 48, 91-97 (2007).

DOI: $10.1016 /$ j.polymer.2006.11.003

[37] Kuznetsov A. A., Semenova G. K.: Perspective thermally stable thermoset binders for polymer composite materials. Russian Journal of General Chemistry, 80, 2170-2180 (2010).

DOI: $10.1134 / \mathrm{S} 1070363210100464$ 